\title{
Choosing the Realist Framework*
}

\author{
Stathis Psillos \\ Dept of Philosophy and History of Science \\ University of Athens \\ Penepistimioupolis (University Campus) \\ 15771 Athens, Greece \\ psillos@phs.uoa.gr
}

\begin{abstract}
There has been an empiricist tradition in the core of Logical Positivism/Empiricism, starting with Moritz Schlick and ending in Herbert Feigl (via Hans Reichenbach), according to which the world of empiricism need not be a barren place devoid of all the explanatory entities posited by scientific theories. The aim of this paper is to articulate this tradition and to explore ways in which its key elements can find a place in the contemporary debate over scientific realism. It presents a way empiricism can go for scientific realism without metaphysical anxiety, by developing an indispensability argument for the adoption of the realist framework. This argument, unlike current realist arguments, has a pragmatic ring to it: there is no ultimate argument for the adoption of the realist framework.
\end{abstract}

"Something went wrong with our standard of reality".

Quine in 'Posits and Reality'

\section{Introduction}

The scientific realism debate has had many dimensions, but a main one has been about the reality of unobservable entities that are typically posited by scientific theories to explain certain observable phenomena and empirical laws. The very idea

\footnotetext{
* Earlier versions of this paper were presented at the Annual Conference of the British Society for the Philosophy of Science, Bristol, July 2007; the Centre for Logic and Philosophy of Science, University of Ghent, December 2007; and the Workshop 'Theoretical Frameworks and Empirical Underdetermination, University of Düsseldorf, April 2008. A number of friends and colleagues have helped me with incisive comments and criticism; here is an incomplete list of them: Dirk Batens, Steven French, Michael Friedman, Michel Ghins, James Ladyman, Robert Nola, David Papineau, Juha Saatsi, Gerhard Schurz, Ioannis Votsis, Erik Weber and John Worrall. Many thanks to all (as well as to an anonymous referee for Synthese).
} 
of unobservability has been repugnant to some philosophers of science. A number of problems have been associated with unobservability. One has had to do with semantics: how can we render language to refer successfully to things that are not given in experience? What could possibly be the locus of meaning of terms (known as theoretical terms) that are supposed to refer to unobservables? Another problem has had to do with epistemology: how can we possibly come to know anything about the unobservable, if the basis of this knowledge is not rooted in experience? A third problem has had to do with metaphysics: what exactly is it to be committed to the reality of unobservable entities? How could positing of unobservable entities be legitimised? Perhaps, a final problem is methodological: in trying to understand science as a practice that involves theory and observation, do we need (and have) to read theories as if they aim to tell a true story about the unobservable world behind or beyond the phenomena?

Why and how these questions arose is a complicated conceptual-historical matter that need not concern us here. The fact is that considerable philosophical weight has been attached to (un)observability and hence to observers in the realism debate. But there is a sense in which the very issue of (un)observability is spurious. That a putative entity is unobservable is, if anything, a relational property of this entity and has to do with the presence of observers with certain sensory modalities (of the kind we have) and not others. That given our sensory modalities some entities have (or acquire) this relational property is something science and common-sense tell us. But the semantic, or epistemological or metaphysical or methodological limitations or restrictions that are supposed to follow from this relational property of some putative entity are imposed by philosophical theories that try to interpret science in a certain way and do not in any way follow from the unobservability per se.

In fact, it seems that stating the realism debate in terms of unobservables obscures a basic feature of a realist approach to science (perhaps to other fields too), viz., that science aims at explanation, which indispensably involves positing microscopic constituents of macroscopic things. Scientific explanation is effected by various ways and there is no overarching way to explain-it consists in findings causes, describing mechanisms, positing more fundamental laws and unifying disparate domains and diverse empirical laws. But in most typical cases, the explanation proceeds in terms of micro-constituents of gross objects, their properties and their relations. 
Placing explanation centre-stage might not be taken to be very empiricist-friendly. One issue-perhaps the most prominent - is that this idea of explanation-bypostulation might raise the spectre of metaphysics, which seems to send shivers down empiricist spines. After all, empiricists tend to rest their philosophical views on more or less everything on the doctrine that all (non-analytic) knowledge stems from (better: is justified on the basis of) experience and they also tend to adhere to the claim that the very issue of how, if at all, (commitment to) the reality of some entities is licensed, can be settled only by appealing to whatever is given in experience.

Can an empiricist be committed to the reality of explanatory posits without opening the floodgates of metaphysics? This question is far from trivial because an outright negative answer to it will land empiricist conceptions of science in the lap of instrumentalism. The latter might have a number of features that are congenial to empiricism (e.g., the emphasis on prediction and control; the insistence that theoretical claims must make a difference in experience, and others). But, on the whole, it is a revisioniary stance to science and, besides, not much less metaphysical than scientific realism, if taken to deny the reality of theoretical posits. (Perhaps, it is less metaphysical, but the denial of a metaphysical thesis is itself metaphysical.) So there had better be an answer to the foregoing question which is positive. In particular, there had better be an answer which steers empiricism clear from the Scylla of metaphysical realism (at least when it affirms that the reality of theoretical entities is transcendent-disconnected from any possibility of knowing them) and the Charybdis of instrumentalism (at least when it altogether denies the reality of theoretical posits).

The required positive answer has been actually advanced by flesh-and-blood empiricists in the first half of the twentieth century. There has been an empiricist tradition in the core of Logical Positivism/Empiricism, starting with Moritz Schlick and ending in Herbert Feigl (via Hans Reichenbach) which has taken it to be the case that empiricism need not be characterised by 'phobia of the invisible and the intangible' as Feigl once put it—after all, this phobia would be uncharacteristic of the empiricist spirit precisely because it would take something other than science, say some philosophical prejudices, as a guide to what there is in the world. According to this tradition, the world of empiricism need not be a barren place devoid of all the explanatory entities posited by scientific theories; and yet, empiricism need not compromise its anti-metaphysical attitude. 
The aim of this paper is to articulate this tradition and to explore ways in which its key elements can find a place in the contemporary debate over scientific realism. It will present a way empiricism can go for scientific realism without metaphysical anxiety, by developing an indispensability argument for the adoption of the realist framework. This argument, unlike current realist arguments, has a pragmatic ring to it: there is no ultimate argument for the adoption of the realist framework. The guiding thought will be that fundamental ontic questions are framework-questions and are not dealt with in the same way in which questions about the reality of ordinary entities (be they stones or electrons) are dealt with-the ontic framework must already be in place before questions about the reality of specific entities are raised.

The realist framework, as I would put the matter, is the framework that posits entities as constituents of the commonsensical entities and relies on them and their properties for the explanation and prediction of the laws and the properties of commonsensical entities. Accordingly, the realist framework is an explanatory framework, viz., a framework of explanatory posits. In particular, it is a framework that explains by positing constituents of macroscopic things. These constituents are typically unobservable-meaning: too little to be registered by our unaided sensory organs. But it is their explanatory role that is important not their relation to observers. Their explanatory role has to do with how they earn their right to be considered real; their observability has to do with how they might become known to observers-these two things have to be kept apart conceptually (though, clearly, observations-perhaps instrument-based observations - can provide good evidence for the reality of an explanatory posit).

\section{From Metaphysical Realism to Empirical Realism}

Logical empiricism has always been animated by an anti-metaphysical attitude. Part of the motivation for verificationism was the thought that it would separate sharply metaphysics from science and would leave the former behind. Schlick took it that the task of metaphysics was to provide an ultimate description of reality, which unravels the true elements of being; the reality as it is in itself. Concomitant to this task was the claim that this description is the product of getting direct insight into reality, 'beyond' or 'behind' what science tells us about it. His critique of metaphysics was based on the claim that the very idea of legitimately admitting something as real requires commitment to the view that it is an object of possible experience. 
The verificationist criterion of meaning was Schlick's way to render his antimetaphysical commitment. Here is a statement of it: "A proposition has a stateable meaning only if it makes a verifiable difference whether it is true or false" $(1932,88)$. This criterion, actually, plays two roles. On the one hand, it is a tool that warns us not to replace one metaphysics with another (e.g., the metaphysics of things-inthemselves with the metaphysics of the given), but rather to leave metaphysics behind, without however leaving behind a rich conception of the world, as this is described by the sciences. On the other hand, it offers a definite way to understand what it is to admit something as being real. As Schlick $(1932,97)$ put it: "When we say of any object or event—which must be designated by a description-that is real this means that there exists a very definite connection between perceptions or other experiences, that under certain conditions certain data appear".

As Feigl (1950) observed, by taking verifiability-in-principle as the criterion of reality, Schlick conflated the evidence there is (or might be) for the reality of an entity and the reality of this entity. Schlick is sometimes guilty as charged. ${ }^{1}$ But there are occasions in which he was very careful to avoid this charge: though verification by reference to the given is the touchstone of meaningfulness, it's a gross misunderstanding to claim that what follows from this is that "only the given is real" (1932, 104). His overall aim (as this is captured in his Positivism and Realism, 1932) was precisely to find a way to steer clear from both instrumentalism and metaphysics by advocating what came to be known as empirical realism—aka consistent empiricism.

The verificationist criterion of meaning was meant to secure the possibility of a middle ground: theoretical entities are no less real than the observable ones, since statements about them are verified (in principle) in the same way as statements about observables (cf. 1932, 101). Hence, there is no special problem with admitting the reality of unobservable entities.

Schlick's empirical realism rests on a literal understanding of scientific theoriestheoretical statements are not re-interpreted; nor are they reduced to whatever can be captured by the data of perception. It is nothing like the philosophy of as-if (theoretical entities are real and not merely useful fictions); nor, of course, is it

\footnotetext{
${ }^{1}$ See Schlick's example of the nucleus (1932, 88-9).
} 
committed only to the empirical adequacy of theories. ${ }^{2}$ As he (1932) makes clear, there are definite empirical criteria to determine when an entity (be it a rock or an electron) exists; as well as to establish that it exists 'independently' of our subjective points of view; that it exists 'externally and independently of us' and the like. These criteria have to do with how beliefs about them are verified.

The target of Schlick's criticism is the view that empirical realism is not realism enough; that empirical reality is not reality enough. What he calls metaphysical realism is the view that there is a world "somehow standing behind the empirical world, where the word 'behind' indicates that it cannot be known in the same sense as the empirical world, that it lies behind a boundary which separates the accessible from the inaccessible" $(1932,102)$. Note that this transcendental world is not the world of electrons and atoms - this is still the empirical world. Schlick's point is that positing such a world makes no verifiable difference. Actually, he $(1932,104)$ noted, there is a difference, but it is only motivational: if we render the world to exist independently of us in a seemingly more robust sense, or if we ascribe to it some kind of transcendent reality, we feel differently (perhaps we are filled with a robust sense of modesty).

So, Schlick's critique of metaphysics (and in particular his critique of metaphysical realism which demands a more robust sense in which theoretical entities are real and independent of the mind, subjective points of view etc.) leaves the world as described by science entirely intact - a world populated by atoms and fields and whatever else our best science tells there is. Science advances by revealing the constituents of things that we encounter in perception and the fact that these are (typically) invisible is no reason to suppose they are not real.

It should be obvious that Schlick has tried to make room for a middle ground between anti-instrumentalism and anti-metaphysics and that this ground was meant to be captured by empirical realism. There are, however, worries with Schlick's commitment to verificationism and its employment in defence of empirical realism. One set of worries has to do with the verificationist criterion of meaning itself. These were advanced by Reichenbach (1938), who argued that it should be replaced by a (weaker) probability theory of meaning. The other set of worries is that Schlick has not yet offered a clear argument for scientific realism. To get to this argument, we need to move ahead first to Reichenbach and then to Feigl.

\footnotetext{
${ }^{2}$ See Schlick's brief comment on Copernicus vs Ptolemy $(1932,105)$.
} 


\section{The Probability of a Framework vs Probabilities within a Framework}

Reichenbach's Experience and Prediction, which was published in 1938, contains an extremely interesting and complex argument for scientific realism. Since I have dealt with it in detail in my (forthcoming), I will only offer here the briefest of sketches of the final part of Reichenach's argumentative strategy, which suggests that the argument for adopting the realist framework is different from the type of argument that licenses acceptance of hypotheses within the framework.

The way I reconstruct it, Reichenbach's $(1938, \S 17)$ key thought was that the very idea of offering arguments for the reality of particular unobservable entities, or of particular microscopic constituents of gross things, requires that a certain framework is already in place that allows positing unobservable entities as a kind of independently existing entities (these are what Reichenbach called 'projective complexes'), distinct from whatever observable effects they might have or marks they may leave. To be sure, he put the point in terms of languages (claiming that adopting realism is a matter of choosing a certain language, that allows us to talk about independently existing physical things (cf. 1938, 145)).

Once this framework is in place, certain assignments of prior probabilities to competing theories become possible, depending on certain plausibility judgements, other background beliefs and such like. But the choice of a framework itself (as opposed to the choice of hypotheses within it) is not (and cannot be) a matter of probability and evidence. We cannot talk of the probability of a framework as a whole, mainly because assignment of probabilities is framework-dependent. The very idea of assigning probabilities to competing hypotheses within a framework requires that the framework is already in place. For instance, we might assign different probabilities to the hypothesis that light is made of corpuscles and that light is made of waves, but this happens because we already work within a realist framework that allows assigning probabilities to hypotheses that posit unobservable entities to explain observable behaviour. But if the choice of the realist framework itself were a matter of probability and evidence, this would require yet another meta-framework within which the realist framework could be placed alongside competing ones in such a way that different probabilities are assigned to them.

The pertinent point that, ultimately, the adoption of the realist framework is not a matter of probabilistic inference. Reichenbach goes on to divide the issue into two 
components - the first is the adoption of a framework as the result of a free (that is, non-dictated by evidence or a priori considerations) decision; the second is the investigation of the adopted framework by looking into its fruits. This consequentialist move is, for Reichenbach, a way to justify the choice of the language (framework) - especially by showing, in a comparative fashion, that one language is better suited than another to achieve certain aims or to satisfy certain desiderata (cf. 1938, 146-7). This last move suggests that the original decision to accept a certain framework (the realist one that Reichenbach favours) is not arbitrary, though not a matter that answers to truth or falsity.

Reichenbach insisted that though the choice of a framework is based on an unforced decision, this decision entails others - this is what he $(1938,13)$ called "entailed decisions"-which, therefore, are far from arbitrary in that one is no longer free not to adopt them if one has already chosen the framework. By examining these 'entailed decisions' certain judgements can be made about the consequences of adopting a certain framework, their plausibility and their fruitfulness. A case which Reichenbach discusses in some detail is the choice between an egocentric framework, in which objects do not exist while unperceived, and a realist one. Even if it is a matter of unforced decision to adopt an egocentric framework, one entailed decision that follows this is the adoption of strange causal laws and an unhomogeneous principle of causation. This principle might be contestable, or implausible, on independent grounds and this would count against the framework that requires it. The very presence of entailed decisions helps to build, as Reichenbach $(1938,15)$ put it, "a dam" against "extreme conventionalism". 3

Reichenbach did argue that the adoption of the realist framework is not a matter to be settled in the same way as the acceptance of scientific theories is settled, viz., by judgements of probability and evidence. So the argument for realism is not based on judgements of probability and evidence. But the choice of realism is not arbitrary either. What considerations then support the choice of the realist framework, even if they do not dictate it? The elements for an answer can be found in Feigl's reformulation of Schlick's empirical realism.

\footnotetext{
${ }^{3}$ Reichenbach's consequentialism fits well with his overall approach to epistemology. He (1938) took it that the critical task of epistemology is to separate the factual from the conventional-a remnant of his Kantian heritage. The conventional element amounts to a decision to adopt a framework. Yet, it is not enough to point out that the choice of a framework does not answer to truth or falsity. Part of the critical task of epistemology is to examine what kinds of consequences follow from the adoption of a certain convention.
} 


\section{Empiricism's Copernican Turn}

Like Reichenbach, Feigl too was dissatisfied with the verificationist criterion of meaning. In particular, he thought it cannot sustain a criterion of reality. According to Feigl $(1950,48)$, verificationism runs together two separate issues: the "epistemic reduction" of an assertion—aka "the evidential basis" for the truth of the assertionand "the semantical relation of designation (i.e., reference)". Verificationism, in other words, conflates the issue of what constitutes evidence for the truth of an assertion with the issue of what would make this assertion true. What Feigl came to call "semantic realism" was put forward as "a corrected form and refinement of the empirical realism held by some logical positivists or empiricists" $(1950,50)$. For him the idea that theoretical terms have (putative) factual reference captures, as it were, the valid residue of claims about independent existence: to say that electrons exist is to say that the term 'electron' has factual reference, that is that there are things in the world which are the referents of the term 'electron'. Unobservable entities are no less real than observable entities, given that, as Feigl put it, "they are on a par within the nomological framework" of modern science (cf. ibid.).

Feigl considered Schlick's empirical realism to be part and parcel of "the gradual liberation of theory from the bondage of metaphysics" (1943[1949], 11), which he took it to be one of the achievements of empiricism. In endorsing empirical realism, Feigl said: "The term 'real' is employed in a clear sense and usually with good reason in daily life and science to designate that which is located in space-time and which is a link in the chains of causal relations. It is thus contrasted with the illusory, the fictitious and the purely conceptual. The reality, in this sense, of rocks and trees, of stars and atoms, of radiations and forces, of human minds and social groups, of historical events and economic processes, is capable of empirical test" (1943[1949], 16).

This, it should be obvious, motivates a criterion of reality which is different from that of verificationism. Here is how he put it: “(...) Reality is ascribed to whatever is required (confirmed) as having a place in the spatio-temporal-causal system" (1950, 51). On this criterion, there is no special problem with being committed to the reality of a host of explanatory posits (typically unobservable entities) assumed by theories, since they are part and parcel of the causal-nomological framework described by science. 
Feigl is not entirely clear as to how exactly he conceives of the realist framework. He $(1950,54)$ describes it as the "conceptual frame of the realist language". But he $(1950,59)$ also talks directly about the realist frame of "space-time-causality-matter". I think it does justice to Feigl to claim that a framework is linguistic only in a derivative way, viz., that we need means to talk (and to form generalisations) about the new type of entity. What matters most is the new type of entity. So, as noted in the Introduction, the realist framework is primarily an ontic framework-it posits (assumes the existence of) a new kind of entity. We could call this type of entity 'unobservable entity' - but as already noted the issue of (un)observability is a red herring. Assuming the life-world we live in, of gross middle-sized macroscopic objects, the realist framework posits a new type of entity: being a constituent of macroscopic entities. The realist framework takes it that the world has a deep structure of microscopic entities which 'make up' the macroscopic ones.

Like Reichenbach but more forcefully than him, Feigl (1950, 54 \& 57) took it that the adoption of the realist framework is not based on the same considerations as the adoption of specific scientific theories, the reason being that the adoption of scientific theories is based - by and large — on their degree of confirmation (that is, on how likely they are given the available evidence). But it does not make sense to talk about the degree of confirmation of the realist framework; the latter should already be in place for the degree of confirmation of certain theories to be possible. In other words, we cannot even start talking about the probability that there are electrons, or quarks or whatever unless we have already adopted the frame of theoretical entities. Feigl too claimed that the adoption of the realist frame is, ultimately, a matter of convention: it is based on a decision to expand the conceptual framework through which we theorise about the world. ${ }^{4}$

Though Feigl echoed Reichenbach's views on entailed decisions, there is a twist in his argumentative strategy in relation to Reichenbach's. The decision to adopt the realist framework, Feigl argued, requires a Copernican turn. Whereas empiricism has

\footnotetext{
${ }^{4}$ Feigl's distinction between metaphysical realism and empirical realism bears some resemblance to Carnap's distinction between external questions and internal ones. In fact, in his Empiricism, Semantics and Ontology, Carnap (1950, 214) refers the reader to Feigl's (1950) piece "for a closely related point of view on these questions [how do we adopt a framework?]". Conversely, in his own defence of semantic realism, Feigl refers the reader to Carnap's (1946, 528), where Carnap says: "I am using here the customary realistic language as it is used in everyday life and in science; this use does not imply acceptance of realism as a metaphysical thesis but only what Feigl calls 'empirical realism". For a brief discussion of Carnap's external/internal distinction, Quine's critique of it and its relevance to the argument of this paper, see the Appendix.
} 
started with the world of experience and has aimed to show how the object of science should be made to fit within the object of perception, realism should take the object of perception to fit within the object of science. Better put, perception is epistemically special because it is through this that human beings get to know what the world is like, but the data of perception (as well as the perceivers) are part of the natural world, as this is described by science, and the question is how they fit into the thus described natural world. As Feigl put it: "The Copernican turn then consists in relating the observer to the observed, the indicator to the indicated,- - not epistemically,- - but so to speak cosmologically" (1950, 41-emphasis added). So: the move from empiricism to scientific realism requires a change of perspective.

\section{An Indispensability Argument for the Realist Framework}

Unlike Kant's own, the empiricists' Copernican turn is not based on a transcendental argument - the claim is not that without realism science would not be possible etc. Though Feigl might not have put it in quite those terms, the argument for the Copernican turn is that the realist framework is indispensable for achieving causal and nomological coherence in our image of the world and for offering cogent explanations of the behaviour of gross objects. ${ }^{5}$ What is more, the realist frame does not leave the world of experience intact. When necessary, it corrects it "from above", as Feigl put it. It corrects empirical laws and explains why certain objects fail to obey certain empirical laws. ${ }^{6}$

Here is how the argument could be stated with a bit more precision.

\section{(A)}

Positing microscopic constituents of gross objects is indispensable for having a causally-nomologically coherent image of the world (viz., a simple and unified system of causal laws). (Relatedly, we cannot have cogent explanations of the behaviour of gross objects (including their deviations from the behaviour predicted by empirical laws) save in terms of positing microscopic constituents.)

\footnotetext{
${ }^{5}$ Feigl did talk about indispensability, when he $(1950,55)$ argued against phenomenalism that it needs to locate in space and time the events that constitute the antecedents and consequents of factual and counter-factual conditionals that are supposed to reduce talk about material objects into a phenomenalistic language. Of this locating and dating, Feigl said that "it indispensably requires the 'realistic' frame".

${ }^{6}$ This kind of argument became famous by Wilfrid Sellars (1963) in his defence of the scientific image of the world. For more on this, see my (2004).
} 
To be an indispensable element of the causally-nomologically coherent image of the world is to be real.

Therefore, the microscopic constituents of gross objects are real.

I assume that the first premise of this argument is now uncontentious, though it was not quite so when Feigl was writing. ${ }^{7}$ So I will focus on the second premise. How and why is indispensability a criterion of reality?

Two thoughts are relevant here; the first concerns indispensability; the second concerns the criterion of reality itself. Let us start with the second thought. If we take the empiricist critique of traditional metaphysics seriously, there is no framework-free standpoint from which what there is (the fundamental building blocks, if you wish) can be viewed. The question of what there is (better: the question of what one is committed to) can only be settled within a framework and its answer has to do with what types of entity have to be assumed for the framework to play the role it is supposed to do. Feigl was particularly keen to block the idea that experienceability is a criterion of reality. If there is more to reality than what can be directly experienced, and if this more should be dissociated from epistemic conceptions as to how it can be known, it is very plausible to think that the touchstone of reality is being part of the causal-nomological structure of the world. The requirement of indispensability strengthens this criterion. Assuming some entities is not enough, if, as Quine (1960, 260) has aptly put it, we have found "a way of accomplishing those same purposes through other channels". If the assumed entities can be dispensed with without failure to achieve what the framework aims to achieve, the question of their reality becomes moot. If, on the other hand, positing these entities is indispensable, there is no residual question to be asked as to whether they are real. For there is no framework-free standpoint from which this further question can be asked.

Is there a tension here? One the one hand, theoretical entities are deemed indispensable $;^{8}$ on the other hand, the decision to adopt the realist framework is an

\footnotetext{
${ }^{7}$ Carnap $(1939,64)$ came close to an argument like this, when he stressed that without using theoretical terms it "is not possible to arrive (...) at a powerful and efficacious system of laws. But he was quite reluctant (at least until the late 1950s) to move from this claim to the indispensability of theoretical entities.
} 
unforced decision. How can that be? The answer, I think, is this. Indispensability arguments work only relative to accepting certain aims. Nothing is indispensable simpliciter. Some things (that is, commitment to the reality of some entities) might be indispensable for a certain purpose or aim. To say that theoretical entities are indispensable is to say that there cannot be (weaker: it's unlikely that there are) ways to fulfil certain aims (advancement of attractive theories, explanation of observable phenomena, predictions of further observable phenomena, development of a unified causal-nomological image of the world) which dispense with positing theoretical entities. But the choice of aims is not forced. One can simply refrain from adopting a certain aim. Hence, there is an implicit or unstated premise in argument (A) above, viz., that aiming for a coherent causal-nomological image of the world is desirable.

We should be careful to distinguish between the realist framework and ordinary scientific theories. The Copernican turn has to do with a change of perspective; a change in the way empiricists view the world: as having a deep structure which grounds/explains its surface structure, i.e., the way it is revealed to cognizers through their sensory modalities. The adoption of the framework implies commitment to theoretical entities through which a coherent causal-nomological view of the world is achieved. Adopting the realist framework does not dictate commitment to any specific scientific theory. This is a matter that has to do with the evidence there is for or against scientific theories. Matters of evidence and justification arise only after the framework has been adopted. What, however, the adoption of the realist framework does dictate is that scientific theories that ostensibly introduce new types of entity should be taken as doing exactly that, viz., as positing entities that explain and predict the behaviour of observables.

It can then be said that the Copernican turn is supplemented with two further points. The first is a criterion of reality: that is real which is required within the causal-nomological frame of science. The second is a criterion for acceptance (or justified belief, if you like): whatever hypotheses are confirmed within this frame are our best candidates for justified belief as to what the world is like. These two points suggest the following: scientific realism asserts the reality of theoretical entities, but which entities we have reason to believe are real is a function of the degree of confirmation of scientific theories.

\footnotetext{
${ }^{8}$ I have used the term 'theoretical entity' because it is customary and because the micro-constituents of macroscopic objects are typically introduced via relatively sophisticated theories of the macro-world.
} 
In what sense are theoretical entities independently existing entities? For an empiricist like Feigl, 'independent existence' is primarily conceived of as existence in its own right, that is irreducible existence. Explanatory posits are not anything else: they are not complexes of data of perception; nor façon de parler, nor useful fictions and the like. Commitment to this kind of independence is licensed by the fact that theories have 'excess content' over whatever could be described in a purely observational language and they are indispensable in explaining why the observable phenomena are the way they are. This might not be taken to be a heavyweight conception of independence. But a) that's precisely the point, viz., that this notion of independence is strong enough to secure commitment to the reality of theoretical entities without creating further metaphysical anxieties; and b) taken in association with the Copernican turn, it does highlight the fact that reality is not constrained by what can be known but by what is required to restore causal-nomological unity to the world.

This, it might be thought, is a weak conception of independence, which might be suitable for empiricists. But is going for it a big concession on the part of realism? Not necessarily. The key point so far is two-fold: a) that the adoption of the realist framework is not based on the same type of argument as the adoption of ordinary scientific theories; and b) that the realist framework is not forced on us either by a priori reasoning or by any empirical facts. This implies that there is an element of choice in adopting realism. But given that a certain aim is chosen, the choice is constrained. The realist framework is indispensable if certain aims are to be achieved or if certain desiderata (some of which might well be dear to its rivals) are to be satisfied. As Grover Maxwell (1962) suggested, a condition of adequacy for a framework suitable for the development of scientific theories is that it should be able to offer explanations of the phenomena. The realist framework satisfies this condition in the best way.

Note that nowhere has it been said or implied that theoretical entities are minddependent. To say that positing theoretical entities is a matter of adopting a framework (and not a matter of direct insight into the metaphysical structure of the world) is not to say that the posited entities are mind-dependent. The act of positing is mind-dependent. But to say that the posited entities themselves are mind-dependent is to say (mutatis mutandis) that scoring a goal in football is mind-dependent-which is not. 
All this is relevant to the status of the no miracles argument. As is well-known, Putnam (and following him Boyd, and following him myself and others) took realism to be a theory and in particular an empirical theory that gets supported by the success of science because it best explains this success. There are quite interesting differences between the exact ways in which Putnam, Boyd and myself conceived of this argument; but the overarching common thought was that realism (as a theory) gets supported by the relevant evidence (the success of science) in the very same way in which first-order scientific theories get supported by the relevant evidence. But scientific realism is not a theory; it's a framework which makes possible certain ways of viewing the world. Scientific realism lacks all the important features of a scientific theory. Even if we thought we could reconstruct scientific realism as a theory for the purposes of epistemology of science, we had better follow Feigl and say: "you can view ordinary realism in analogy to scientific theories, but be careful in doing so!". The problem lies in the thought that scientific realism can be supported by the same type of argument that scientific theories are supported. This is a tempting thought. But it is flawed, I now think. The reason for this claim is that the very idea of counting empirical success as being in favour of the truth of a scientific theory-the very idea of evidence making a theory probable, or the very idea that a theory is the best explanation of the evidence, and the like-presupposes that theories are already placed within the realist framework. For the no-miracles argument to work at all it is presupposed that explanation-and in particular explanation by postulation-matters and that scientific theories should be assessed and evaluated on explanatory grounds. Hence, the no-miracles argument works within the realist framework; it's not an argument for it. ${ }^{9}$ It presupposes rather than establishes the realist frame. Still, within the realist framework, the no-miracles argument has an important role to play, and this, as I have argued in my (1999), is to offer a vindication of inference to the best explanation. ${ }^{10}$

\footnotetext{
${ }^{9}$ A recent paper which casts fresh light on the role of the no-miracles argument in the realism debate is Ghins (2001).

${ }^{10}$ The way I read it, the no-miracles argument is a philosophical argument that aims to defend the reliability of scientific methodology in producing approximately true theories and hypotheses (see my 1999, 78-81). Its conclusion proceeds in two steps. The first step is that we should accept as (approximately) true the theories that are implicated in the (best) explanation of the instrumental reliability of first-order scientific methodology. The second step is that since, typically, these theories have been arrived at by means of IBE, IBE is reliable. What makes the no-miracles argument distinctive as an argument for realism is that it defends the achievability of theoretical truth. The second step of the conclusion is supposed to secure this. The background scientific theories, which are
} 
By the same token, sweeping agnosticism towards theoretical entities is an oddity! One can certainly be agnostic about specific posits (e.g., dragons or electrons). This kind of stance is fine, since there may not be enough evidence for them. But can one coherently be agnostic about the framework while one is using it? Can one neither affirm it nor deny it, but nonetheless employ it (perhaps with an as-if operator in the front) and reap its fruits? I doubt this can be done coherently within the framework. A sweeping agnostic seems to intend to occupy a position within the framework (by using it to explain and predict) and at the same time outside the framework (by treating it as a useful fiction). One can, of course, deny the framework and adopt a different one, viz., a fictionalist one. But this is not agnosticism.

Given that the realist framework is adopted, the claim that there are theoretical entities cannot be coherently denied unless the realist framework is abandoned. It is constitutive of the framework. The framework itself, however, is not an object of belief or doubt. It can either be shown to be dispensable or less efficient than others when it comes to achieving a certain aim. Specific theories within the framework, or specific commitments within it (e.g., concerning electrons), can be doubted and challenged. These will be epistemic doubts having to do with evidence and possible specific explanatory alternatives.

\section{A Concluding Remark}

With all this in mind, we can say that the adoption of the scientific realist framework is based on the indispensability of theoretical entities for the explanation of observable phenomena and for achieving maximum causal and nomological coherence in our image of the world. Theoretical entities are indispensable for the causal unity of the world. Theoretical entities ensure enhanced predictability of, and control over, nature. Their presence makes a difference to what can be predicted (see the case of novel predictions), to what kinds of interventions can happen in the world (see the manipulations of theoretical entities in controlled experiments) and to what corrections can be made to empirically established regularities (see the revision/correction of the manifest image of the world). Relative to these aims, there

deemed approximately true, have themselves been arrived at by abductive reasoning. Hence, it is reasonable to believe that abductive reasoning is reliable: it tends to generate approximately true theories. 
is simply no framework that can do a better job at achieving them than the realist one. This is already enough of an argument for realism, even though it is not an ultimate argument for realism.

\section{Appendix}

The reader will rightly wonder how the above relate to Carnap's distinction between external and internal questions and to Quine's critique of it. Because this matter is quite complex, it cannot be treated in a (long) footnote. Actually, it can be argued that historically and conceptually Carnap and Quine offered two distinct (but in an important sense related) ways to develop the rapprochement between empiricism and scientific realism, as this was developed in the Schlick-Reichenbach-Feigl tradition of empirical realism.

The way I read it, Carnap (1950) wanted to exclude external theoretical questions. What are they? These are questions about the reality of a general type (or category) of entity which are supposed to be settled by looking for (empirical) evidence for the reality of this type or by insight into the metaphysical structure of the world, and whose answer is supposed to be the content of a belief-like propositional attitude. Carnap denied that a question of the sort 'Are there entities (of type) X?' has any cognitive content, if it is meant to be asked as an external theoretical question. Differently put, questions concerning the reality of a type of entity are legitimate and have content, but only if they are taken to be either external practical questions concerning the benefits of adopting a certain framework which includes this type of entity in its basis ontic inventory or as internal theoretical questions concerning the evidence there is for (or other reasons for accepting the reality of) certain tokens of this type, but only after a framework has been adopted.

Famously, Carnap thought that external practical questions are answered by the adoption of linguistic frameworks. A linguistic framework is characterised by the adoption of a new type of concept, suitable for the new type of entity, and a new type of variable, ranging over instances of the new type of entity. This kind of way to view the framework was part of the reason why Quine (1951) was very critical of Carnap's distinction. He thought that the external/internal distinction amounted to a proposal to segregate variables: it distinguished between category questions (which purported to exhaust the range of a particular variable) and subclass questions (which did not exhaust the range of this variable). Quine rightly thought that this was wrong. 
But Quine agreed with Carnap (and with Schlick, Reichenbach and Feigl) on a fundamental point, central to the issue we have been discussing, viz., that there is no theory-free standpoint from which what there is can be viewed. For him, however, there is no sharp line between theoretical issues (or questions) and practical ones. Ontological questions (questions about what there is) are theoretical questions as well as practical ones: they are answered by best theory and there is no extra-theoretical court of appeal. The best theory just is the theory that works sufficiently well-in particular the theory that tallies with the evidence and satisfies a number of virtues, most notably simplicity. For Quine, the utility of a posit and its reality go hand in hand. $^{11}$

There are a number of subtle issues to be discussed here (mostly concerning Quine's naturalism and his view that the external/internal distinction is another way to render the analytic/synthetic distinction); but we shall not deal with them presently. ${ }^{12}$ Instead, I will sum up the two ways to articulate Carnap's and Quine's common thought that there is no theory-free standpoint from which what there is can be viewed.

If we go Carnap's way, then:

1. Commitment to the reality of a general type (or ontic category) of entity is not at the same level (and is not governed by the same rules) as commitment to particular entities of this type.

2. Commitment to the reality of a general type of entity is not a matter of evidence; nor a matter of insight into the metaphysical structure of the world; nor a matter of adopting a theory (like an ordinary scientific theory). It is a matter of adopting a framework which posits this type.

3. The adoption of the framework is not a theoretical issue (though it is influenced by theoretical considerations.

If we go Quine's way, then 'framework' principles are, in essence, the most general hypotheses of our overall theory of the world:

\footnotetext{
${ }^{11}$ Though Carnap did insist on the practical-theoretical distinction, he did not think there was no giveand-take between the two: theoretical considerations can and do influence practical decisions and conversely.

${ }^{12}$ For a very nice recent account of the issue between Carnap and Quine concernign ontology, see Alspector-Kelly (2001).
} 
1'. There is no difference between the framework and the theories within it. The framework is a theory (perhaps a general one) and is judged using the same evidential standards and pragmatic considerations as in the case of ordinary theories.

2 '. The entities we are committed to are those that are required for the truth of our overall best theory of the world. These are real entities in the only sense we can make of the word 'real'.

3'. The best theory of the world is the theory licensed by the scientific method.

The appearance of a gulf between Carnap's way and Quine's way might fade away if we take on board Quine's distinction between ontology and ideology. In his (1951a, 13), he noted: "For the universal and existential quantifiers mean simply 'every entity (of appropriate type) is such that' and 'some entity (of appropriate type) is such that'. The theory presupposes all and any of those entities whose nonoccurrence within the ranges of the variables of quantification would render parts of the theory false. There is doubtless more to metaphysics than ontology in the above sense; and some of this additional matter is perhaps thought of also as ontology in some sense" (1951a, 13). This 'additional matter' is what Quine calls "ideology": "I have described the ideology of a theory vaguely as asking what ideas are expressible in the language of the theory" (op.cit., 15). As he put it in $(1983,501)$, the ideology of a theory is "a stock of simple and complex terms or predicates".

Quine did not develop this notion of ideology further, but it seems that a fruitful way to go ahead is to say that ideology goes beyond ontology because it deals with the prior issue of what general types (categories) of entity a theory assumes. The ideology provides the framework within which questions of ontology (in the Quinean sense of it) can be raised. Consider then the following two kinds of question:

(A) what entities is a scientific theory (e.g., the electron theory) committed to?

(B) what kinds of entity are required if a coherent causal-nomological image of the world is to be achieved?

Carnap would have it that (B) is a framework question. Carnap's thought was precisely that (B) is not answered by metaphysical insight—or by telling the correct metaphysical story, as if there were theory-unmediated access to the world. A Quinean might well take (B) to be a question of ideology. To see how this can be, let 
us consider a familiar example. Consider advocates of the kind of instrumentalism based on Craig's theorem). They replace all theories with their Craig-transforms, which, as is well-known, is devoid of theoretical terms. Take a 'theory' Craig(T) of T. Questions of type (A) can surely be raised vis-à-vis Craig(T). If, for instance, $T$ is the theory of electrons, its Craig (T) does not assume any electrons. But questions of type (B) are of a different order. They do not concern individual theories but whether or not a framework is accepted which dispenses altogether with theoretical terms and their putative reference to theoretical entities. Put in Quinean terms, whether or not we should we go for Craig(T) type of theories is a matter of ideology—of what types of entity are allowed or admitted. Put in Carnapian terms, it is a matter of adopting a framework.

The way I would put the general point is this. Admitting instances of an ontic category requires admitting (assuming the existence of) the category. And admitting an ontic category is basically admitting a framework (or an ideology) within which this category plays an explanatory role.

\section{References}

Alspector-Kelly, M. (2001). On Quine on Carnap on Ontology. Philosophical Studies, 102, 93-122.

Carnap, R. (1939). Foundations of Logic and Mathematics. International Encyclopaedia of Unified Science, 1, No.3. Chicago: The University of Chicago Press.

Carnap, R. (1950). Empiricism, Semantics and Ontology. Revue Intérnationale de Philosophie, 4, 20-40—reprinted in Meaning and Necessity: A Study in Semantic and Modal Logic. (1956). Chicago: The University of Chicago Press.

Carnap, R. (1946). The Two Concept of Probability. Philosophy and Phenomenological Research, 5, 513.

Ghins, M. (2001). Putnam's No-Miracle Argument: A Critique. In S. P. Clarke and T. D. Lyons (Eds.) Recent Themes in the Philosophy of Science. Kluwer Academic Publishers.

Feigl, H. (1943[1949]). Logical Empiricism. In D. D. Runes (Ed.) Twentieth Century Philosophy, New York: Philosophical Library.- reprinted in H. Feigl and W. Sellars (Eds.) Reading in Philosophical Analysis. New York: Appleton-CenturyCrofts, Inc. 
Feigl, H. (1950). Existential hypotheses: Realistic versus Phenomenalistic Interpretations. Philosophy of Science, 17,35-62.

Psillos, S. (1999). Scientific Realism: How Science Tracks Truth. London: Routledge.

Psillos, S. (2004). Tracking the Real: Through Thick and Thin. The British Journal for the Philosophy of Science, 55, 393-409.

Psillos, S. (forthcoming). On Reichenbach's Argument for Realism. Synthese.

Quine, W. v. O. (1951). Carnap's Views on Ontology. Philosophical Studies, 2, 6572—reprinted in The Ways of Paradox and Other Essays, (1966) Cambridge MA: Harvard University Press.

Quine, W. v. O. (1951a). Ontology and Ideology. Philosophical Studies, 2, 11-15.

Quine, W. v. O. (1960). Word and Object. Cambridge MA: MIT Press.

Quine, W. v. O. (1983). Ontology and Ideology Revisited. The Journal of Philosophy, 80, 499-502.

Reichenbach, H. (1938). Experience and Prediction. Chicago: The University of Chicago Press.

Sellars, W. (1963). Science, Perception and Reality. (re-issued 1991).Atascadero CA: Ridgeview Publishing Company.

Schlick, M. (1932). Positivismus und Realismus. Erkenntnis, 3, 1-31. Transl. As "Positivism and Realism" in Alfred J. Ayer (Ed.) Logical Positivism. 1960. Glencoe, NY: Free Press,. 